\title{
Increasing the Corrosion Resistance of Mullite-based Catalyst Substrates in a Vehicle Exhaust Environment
}

Clifford S. Todd ${ }^{1}$, Michael Malanga ${ }^{2}$, Robin Ziebarth ${ }^{1}$, Kevin Howard ${ }^{1}$, Robert Newman ${ }^{1}$, Alexander Pyzik $^{1}$, Daniel Grohol ${ }^{1}$, Nick Shinkel ${ }^{1}$, Niladri Das ${ }^{2}$

1. Core Research \& Development, The Dow Chemical Company, Midland, MI, USA

2. Dow Automotive, The Dow Chemical Company, Midland, MI, USA

Catalyst substrates used in combustion engine vehicles must withstand the harsh environment of elevated temperatures with exposure to corrosive gasses while in contact with catalytic materials. Typical temperatures are $200-300^{\circ} \mathrm{C}$, but can reach as high as $1000{ }^{\circ} \mathrm{C}$ for short periods of time.

A catalyst substrate created from clay and alumina precursors processed at high temperatures in a $\mathrm{SiF}_{4}$ environment results in a porous ceramic that is typically more than $95 \%$ mullite. Impurities incompatible with the mullite crystal structure become concentrated in a residual silicate glass, mostly located at mullite grain intersections. Microanalysis of this catalyst substrate after exposure to onengine conditions identified that corrosion of intergranular silicate glass occurred. Mullite crystals showed no signs of corrosion.

Corrosion of the glass had two characteristics. One was the migration of $\mathrm{MgO}$ from the silicate glass into the adjacent $\gamma$-alumina based catalyst coating. A zone of Mg-enrichment $\sim 200 \mathrm{~nm}$ thick developed where glass was in contact with alumina coating (Figure 1). No other elements were found to migrate either way across this interface.

The second characteristic of the corrosion was disappearance of glass from some locations. Before corrosion, glass typically filled mullite grain junctions, forming smooth fillets. Microscopy of grain boundaries before and after corrosion showed that in some places glass was no longer there. Our hypothesis is that the glass re-melted and flowed away from these locations (Figure 2).

A research effort was undertaken to increase the corrosion-resistance of the ceramic. Simply removing $\mathrm{MgO}$ from the existing formulation was not an option because its absence was detrimental to the desired ceramic microstructure. We discovered a new formulation that maintained the overall product microstructure, but rendered the silicate glass stable when catalyst-coated and exposed to accelerated aging in vehicle exhaust environments. 


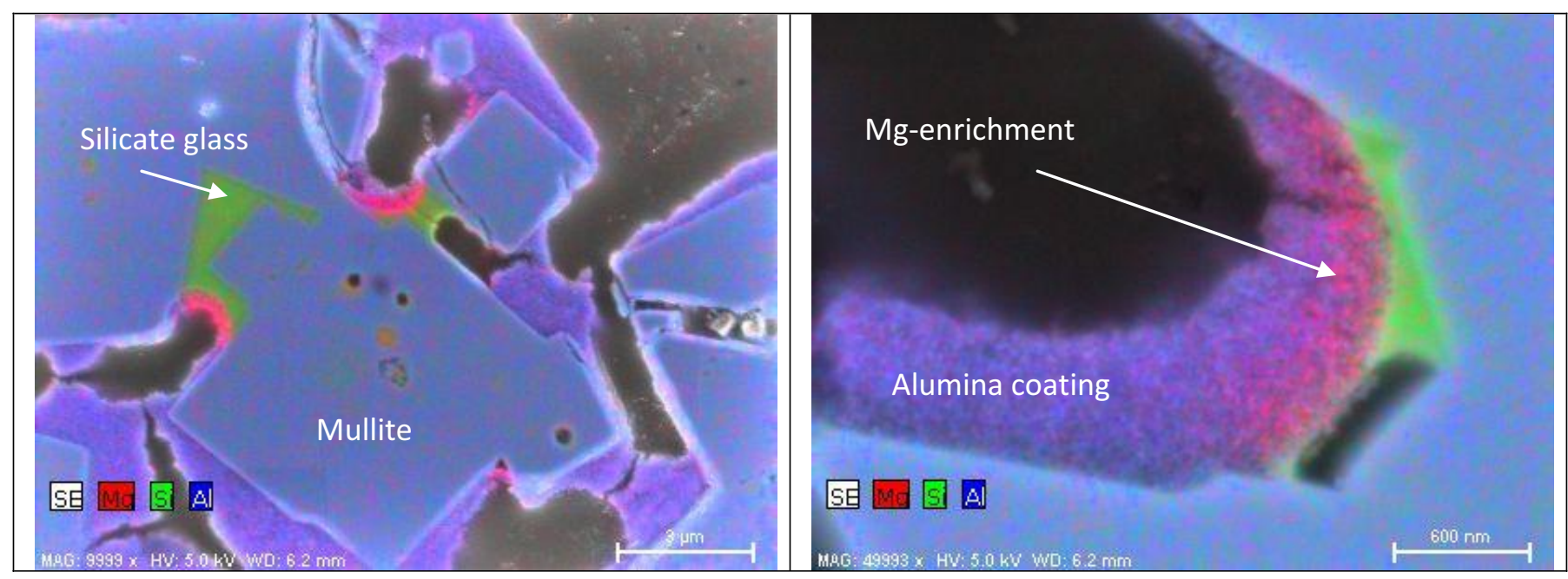

Figure 1. Embedded/polished cross section through sample. EDS element maps overlain on SEM image. $\mathrm{Red}=\mathrm{Mg}$, Green $=\mathrm{Si}$, Blue $=\mathrm{Al} . \mathrm{MgO}$ migrated from the glass into adjacent alumina coating where the two were in contact.

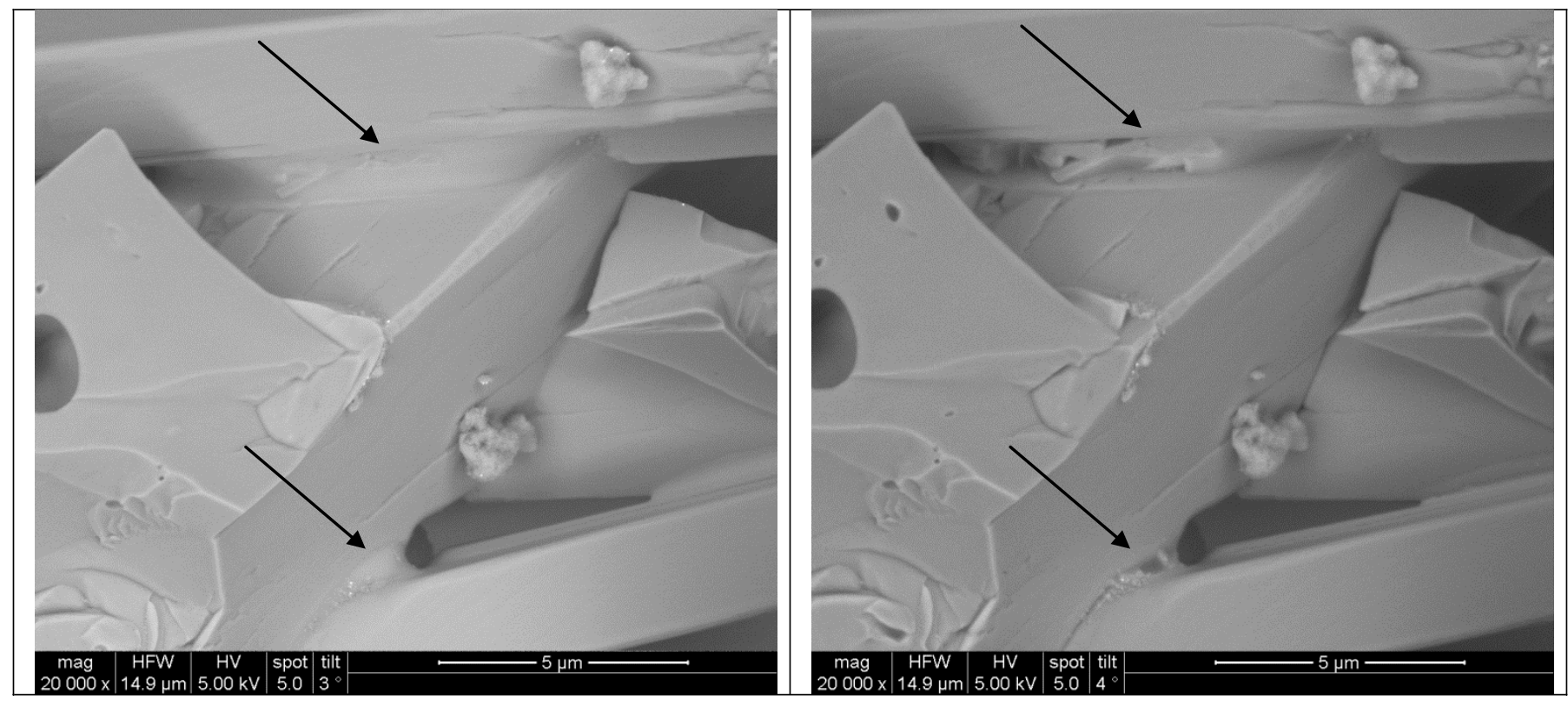

Figure 2. SEM images of catalyst-coated substrate before (left) and after (right) accelerated exposure to a vehicle exhaust environment. The silicate glass at grain intersections moved during exposure. 